\title{
Risk of Anterior Cruciate Ligament Injury in Obese Population: A Retrospective Study in a Single Center in Saudi Arabia
}

\author{
Hasan Alsayed \\ Imam Abdulrahman Bin Faisal University King Fahd Hospital of the University \\ Mohammed Alkhateeb \\ Imam Abdulrahman Bin Faisal University King Fahd Hospital of the University \\ Asma Abdulaziz Aldossary ( $\sim$ Asmaaldossary81@gmail.com ) \\ 0001-5571-1502 \\ Khalid Houbani \\ Imam Abdulrahman Bin Faisal University \\ Yousef AlJamaan \\ Imam Abdulrahman Bin Faisal University King Fahd Hospital of the University \\ Dakheel Aldakheel \\ Imam Abdulrahman Bin Faisal University King Fahd Hospital of the University \\ Yousef Alrashidi \\ Taibah University
}

Imam Abdulrahman Bin Faisal University King Fahd Hospital of the University https://orcid.org/0000-

\section{Research article}

Keywords: Anterior cruciate ligament (ACL) injury, elevated BMI, modifiable risk factors

Posted Date: June 4th, 2020

DOI: https://doi.org/10.21203/rs.3.rs-32771/v1

License: (c) (i) This work is licensed under a Creative Commons Attribution 4.0 International License. Read Full License 


\section{Abstract}

Background: The Anterior cruciate ligament (ACL) injury is among the most common orthopedic injuries(1). The Elevated Body Mass Index (BMI), can contribute to non-contact ACL injury(5). This study aims to assess \left. the risk of (ACL) injury in obese people (BMI) more than $30{\mathrm{Kg} \backslash \mathrm{m}^{2}}^{2}\right)$.

Methodology: This is a retrospective cohort series was done in a tertiary care center in Kingdom of Saudi Arabia . A total of 302 patients, who had ACL reconstruction surgery in a period between (January 2008 to December 2018) were included. (BMI) was classified based on WHO classification, baseline characteristics data include: Age, gender, nationality, type of injury, classification of injury, mechanism of injury, and mode of injury. Binary regression analysis was done to predict the effect of obesity on a selected baseline characteristic of patients (type of sport, Isolated $\backslash$ combined, type of injury, reinjury rate).

Result:

Our study showed that sport related injury is significantly higher among overweight and obese group ( $\mathrm{P}$ : $0,007)$. Moreover, the combined ACL tear was higher among overweight and obese group (P: 0,001). In binary regression analysis for the selected baseline characteristics we found that obese people have chance to develop combined $(A C L)$ injury 2 times higher when compared to those with isolated $A C L$ injury with a $p$ value of $(0,003)$. However, the other selected variables like mode of injury, type of sport, mechanism of injury and type of graft were not significance.

Conclusion: Elevated BMI was associated with higher risk of developing ACL tear.

\section{Background}

Anterior cruciate ligament $(\mathrm{ACL})$ tear is among the most common orthopedic injuries ${ }^{[1]}$. The annual ACL injury rate in United States is reported to be between $100000-200000^{[2,3]}$. Many factors have been associated with ACL injury including modifiable and non- modifiable risk factors; however, understanding the modifiable risk factors is crucial in employing preventative measures ${ }^{[4]}$. One of the modifiable risk factors is an elevated body mass index (BMI), which can contribute to development of non-contact ACL injury [5]. Thein et al reported that the elevated BMI in both genders associated with increasing the rate of knee injuries ${ }^{[6]}$. Noyes FR et al. reported a $75 \%$ of ACL injuries were due to non- contact mechanism ${ }^{[7]}$. World Health Organization )WHO (classified the BMI with more than $30 \mathrm{~kg} \backslash \mathrm{m}^{2}$ as obesity, and BMI between $25-30 \mathrm{~kg} \backslash$ $\mathrm{m}^{2}$ as overweight ${ }^{[8]}$. In Kingdom of Saudi Arabia (KSA), the prevalence of overweight is $30.7 \%$ in male and $28.4 \%$ in female population. Moreover, the prevalence of obesity is more in female, accounting for $23.6 \%$ compared with $14.2 \%$ in male population ${ }^{[9]}$. Although obesity is an emerging health issue in KSA and ACL injury is one of the most common injuries faced by orthopedic surgeons, there is only one study held in Riyadh, KSA that asses the association between these variables ${ }^{[1,9]}$. The aim of this study is to evaluate the risk of $A C L$ injury in obese people (BMI more than $30 \mathrm{~kg} \mathrm{~m}^{2}$ ) in a single tertiary care center is Saudi Arabia- AL Khobar. 


\section{Methods}

A cohort retrospective study was done in a tertiary care center at Al Khobar, KSA after an institutional review board approval. The data were gathered from January 2008 to December 2018. Patients' demographics and other variables were obtained via an electronic file system. Three hundred and two patients were in included in this study, 13 patients were excluded due to missing of data, so the total was 289 . We included all patients who underwent ACL reconstruction using either semitendinosus or bone-tendon bone autograft or allograft. We compared the rate of isolated anterior cruciate ligament tear, multi-ligamentous tears and associated meniscal injuries between different patient's BMI groups in conjunction with baseline variables. Multi-ligamentous tears were defined as an ACL tear plus one or more of the following: medial collateral ligament, the lateral collateral ligament and posterior cruciate ligament tears. Both partial and complete tears were considered and summited together. Patients' data were obtained including the date of admission, duration of injury, and date of surgery along with height $(\mathrm{m})$ and weight $(\mathrm{kg})$ resembled in (BMI). The sample was categorized into three main categories, based on WHO classification of BMI, namely: the normal BMI group (17.9-24.9), overweight (25-29.9), and obese group. The obese group includes the three main classes, Class I is for BMI between(30- 34.9), Class II (35- 39.9) and (Class III for BMI of 40 and above). Mechanism of injury involving the type of sport, either contact sports (e.g. football and basketball), non-contact sports (e.g. jogging and jumping) or non-sport injuries (e.g. falls), were considered. Presence or absence of surgical revision were documented.

\section{Statistical Analysis}

Data analysis was done using Statistical Packages for Software Sciences (SPSS) version 21 Armonk, New York, IBM Corporation. Data are described using numbers and percentages for all categorical variables. Chi square test was utilized to calculate the relationship between dependent and independent variables. The accepted P-value as a significant level is $\leq 0.05$ for all statistical tests. Furthermore, binary regression analysis has been utilized to predict the likelihood effect of the dependent variables against independent factors where the odds ratio and $95 \%$ confidence interval were also being shown.

\section{Results}

The baseline characteristics of patients are represented in (Table 1). The age range was from 12 to 55 years old (mean $28.3 \pm 7.5 \mathrm{SD}$ ). Nearly all participants were males $(98.3 \%)$ and mostly Saudis (99\%). Additionally, about $(70 \%)$ of accident were due to sport activities while (30.4\%) were due to non-sport. With regards to the type of sport, football was played by $(63 \%)$ of participants, $(1.4 \%)$ played basketball, while other sports such as swimming and running were composed of $(5.2 \%)$ whereas $(30.4 \%)$ of participants had been categorized in a non-sport group. The mean BMI of participants was 27.6 (SD 4.8) where normal BMI was composed of (29.8\%), overweight was (40.1\%) and the rest were obese (30.1\%). There were cases of $(60.9 \%)$ referring to combined ACL tear and (39.1\%) cases of isolated ACL tear. With regards to classification of injury, a high proportion of injury were sustained from non-contact $(66.4 \%)$ whereas $(33.6 \%)$ sustained from contact. Moreover, A higher proportion (56.4\%) of injuries of were due to twisting mechanism, (30.8\%) were a result of trauma and the rest occurred from fall (12.8\%). More than a half of patients had right side injury $(54.7 \%)$, 
whereas left sided injury were (44.6\%) and 2 cases were bilaterally injured. In the course of injury, about a half of patients (49.5\%) waited 1 to 3 years of ACL till the time of procedure, followed by $(30.0 \%)$ which waited less than a year and the rest were either more than 3 years or less than a month of time. With regards to the type of graft, almost all patients (93.7\%) accounted to have semi-T where the source was mostly autograft $(99 \%)$. Also, about three out four patients documented to have first time of exposure to ACL injury.

When measuring the relationship between BMI group and the baseline characteristics of patients, we found that sport related injury is significantly higher among the overweight and obese group $(p-0.007)$ for which, football was the most significant in compare with other sports ( $p-0.003)$. Combined ACL tear cases are significantly higher among obese and overweight group; the calculated $p$ value was $(0.001)$. However, the patients with normal BMI was significantly less likely to be reinjured, P-value of (0.029). On the other hand, age group in years, gender, leg injured, classification of injury, mechanism of injury, type of graft and source of graft were not statistically significant to BMI group (Table 2).

In binary regression analysis, we discovered that the chance of obese patients of having combined ACL injury is 2 times higher compared to those with isolated ACL injury (Adjusted odds ratios AOR) $=2.367 \mathrm{p}$ 0.003). Other variables included in this study such as type of sports, type of injury and mode of injury revealed to have no significant effect in the obesity group of patients (Table 3 ).

\section{Discussion}

Our study focused on addressing the association between elevated (BMI) and (ACL) injury, understanding the association between these variables is highly important specially in our population as the overall prevalence of obesity Saudi Arabia is around $35.6 \%$, and the overweight is $36.9 \%$ that makes $72.5 \%$ of population are either overweight or obese (10). Surprisingly, our study showed that the injured patients were obese and overweight around (30\%) and (40\%) respectively, which account for $70 \%$ of the total patients.

Thein et al reported that increased BMI in both genders is associated with elevated prevalence of knee injuries but was more significant in female subjects with respect of having more associated meniscal and ligamentous injuries ${ }^{[6]}$. However, most of the participants in this study were males accounting for $98.3 \%$, while the female accounts for $1.7 \%$ of subjects. Furthermore, in our study, there was no significance association between the different BMI groups and gender (P-value: 0.220 ).

In our study, obese patients were more prone to develop knee injuries compared to normal BMI patients with a $p$ value of (0.004). There was a significant difference in the reinjury rate, which was significantly less in normal BMI group with a P-value of (0.029). The risk of ACL tears and particularly combined ACL tears were significantly higher across obese patients as well as overweight patients with a $p$ value of (0.001). AlJassir et al study showed that elevated BMI is not a risk factor for developing non-contact $A C L$ injury with a $p$ value of $(0,697)$, however, they were not sure whether the BMI was changed time of injury and the time of surgery [10].

A recent systematic review showed that the non-contact injuries in normal BMI subjects account for $49 \%$; while in elevated BMI subjects, the non- contact injuries reach $40 \%$, which indicates no significance 
difference between the two groups ${ }^{[5]}$. However, regarding to the mechanism of injury; Ballal et al reported that there is no significance difference between normal (BMI), overweight and obese. However, this study also showed that there is insignificance difference in the mechanism of injury between the three groups (Pvalue: 0.59$)^{[11]}$.

Our research focuses on the important role of elevated BMI and its positive relationship to ACL injury. BMI is one of the modifiable factors, so understanding the relationship between these variables will give us an opportunity to improve the prevention strategies of ACL injuries. According to Bojicic et al, it has been shown that subjects with elevated BMI had higher risk to develop ACL injuries. They looked at BMI as a modifiable risk factor and posterior tibial slope as non-modifiable risk factor and concluded that the BMI contributes in exacerbation of the positive correlation between posterior tibial slope and ACL injury risk. And their suggestions were toward the athletes who are recommended to increase their weight should decrease their weight as an effective way to decrease their risk of developing ACL injury ${ }^{[12]}$. Derraik et al reported an association between patients with elevated $\mathrm{BMI}$ and the progressive decrease in physical functions, therefore such a deficit can include patients who suffer from orthopedic diseases such as ACL injuries

${ }^{[13]}$.Identifying and understanding the risk factors and the mechanism of ACL injury are of great importance for the patients and clinician as it helps to design neuromuscular training programs for athletes ${ }^{[14]}$. Our study showed that patients with elevated BMI had higher risk for developing ACL tear. Moreover, BMI has been showed to contribute to exacerbation of the positive correlation between elevated $\mathrm{BMI}$ and risk of $\mathrm{ACL}$ tears.

The limitation of our study, BMI was only measured at time of admission to the hospital and may not indicate the true BMI measure at time of injury.

Understanding the association between elevated BMI and ACL injury is important in implementation of the appropriate preventive measures. Recent literature suggests having an elevated BMI is a modifiable risk factor for ACL injury. Many questions remain unanswered, including the type of body fat mass versus the lean and how much is the hazardous amount of weight gain, all these questions could be the target of future researches .

\section{Conclusion}

In conclusion people with more than accepted BMI level will be at higher risk of having ACL tear. In other words, the BMI elevation is associated with developing ACL tear. Understanding the relationship between ACL injury and modifiable risk factors which include elevated BMI is important in implementation of the preventive measures of ACL injury.

\section{List Of Abbreviations}

(ACL) Anterior cruciate ligament ; (BMI) Body Mass Index ; (WHO) World Health organization; (KSA) Kingdom of Saudi Arabia ; Statistical Packages for Software Sciences (SPSS); Adjusted odds ratios (AOR); 


\section{Declarations}

\section{Acknowledgments:}

Not applicable

\section{Author's Contributions:}

Alsayed $\mathrm{H}$ was involved in the study design, critical revising of the first draft of the proposal ,revising the statistical analysis, and editing and revising the initial and final draft of the manuscript; and in the final approval of the version of the article to be published.. Alkhateeb $M$ and Houbani $K$ involved in the literature review ,study design, writing the proposal, gaining ethical approval, data sheath formation, statical analysis and data collection, writing the initial draft of manuscript. Aldossary A involved in literature review, writing the proposal, data collection, writing the initial draft of manuscript, editing and revising the final draft of the manuscript; ALjamaan $Y$ was involved in supervising the data collection process, revising the first draft of proposal and writing the first draft of the manuscript. Aldakheel $D$ was involved in the revision of the final draft of manuscript. Alrashidi $Y$ involved in revising and editing the final draft of the manuscript, critical revisions related to important intellectual content of the manuscript; and in the final approval of the version of the article to be published.

\section{Funding:}

Not applicaple

\section{Availability of the data:}

The datasets used and \or analyzed during current study are available from the corresponding author on reasonable request.

Ethics approval and consent to participate : The researcher received ethical clearance and approval from institutional review board of imam Abdulrahman bin Faisal university (IRB Number -UGS-2018-01-243) on Wednesday, December 5, 2018. Patients were not required to give informed consent to the study because the analysis used anonymous clinical data that were obtained after each patient agreed to treatment by written consent

Consent for publication : Not applicable.

Competing interest: The authors declare that the have no competing interests.

\section{References}

1. Spindler KP, Wright RW. Clinical practice. Anterior cruciate ligament tear. N Engl J Med. 2008;359:2135. [PMID: 19005197 10.1056/NEJMcp0804745].

2. Albright JCCJ, Graf BK, Richmond JC. Knee and leg: soft tissue trauma. In: JH. B, editor. Orthopaedic Knowledge Update 6. Rosemont American Academy of Orthopaedic Surgeons; 1999. p. 533. 
3. Gordon MDSM. Anterior cruciate ligament injuries. In: JG G, editor. Orthopaedic Knowledge Update Sports Medicine III,. Rosemont American Academy of Orthopaedic Surgeons; 2004. p. 169.

4. Uhorchak JM, Scoville CR, Williams GN, Arciero RA, St Pierre P, Taylor DC. Risk factors associated with noncontact injury of the anterior cruciate ligament: a prospective four-year evaluation of 859 West Point cadets. Am J Sports Med. 2003;31:831. [PMID: 14623646 10.1177/03635465030310061801].

5. Pfeifer CE, Beattie PF, Sacko RS, Hand A. RISK FACTORS ASSOCIATED WITH NON-CONTACT ANTERIOR. CRUCIATE LIGAMENT INJURY: A SYSTEMATIC REVIEW. Int J Sports Phys Ther. 2018;13:575. [PMID: 30140551.

6. Thein R, Hershkovich O, Gordon B, Burstein G, Tenenbaum S, Derazne E, Tzur D, Shamis A, Afek A, Kreiss Y. The Prevalence of Cruciate Ligament and Meniscus Knee Injury in Young Adults and Associations with Gender, Body Mass Index, and Height a Large Cross-Sectional Study. J Knee Surg. 2017;30:565. 10.1055/s-0036-1593620]. [PMID: 27880969.

7. Noyes FR, Mooar PA, Matthews DS, Butler DL. The symptomatic anterior cruciate-deficient knee. Part I: the long-term functional disability in athletically active individuals. The Journal of bone joint surgery American volume. 1983;65:154. 10.2106/00004623-198365020-00003]. [PMID: 6687391.

8. WHO expert committee. Interpretation of A. In: World Health O. Physical status: the use of and interpretation of anthropometry. Geneva: World Health Organization; 1995.

9. Al-Othaimeen Al, Al-Nozha M, Osman AK. Obesity: an emerging problem in Saudi Arabia. Analysis of data from the National Nutrition Survey/L'obesite: un probleme emergent en Arabie saoudite. Analyse des donnees de l'Enquete nationale sur la Nutrition. Eastern Mediterranean Health Journal 2007; 13: $441+$ [PMID.

10. ALJassir F, Nasser A, Bin Khidhr R. The anthropometric measurements as predisposing factor for noncontact anterior cruciate ligament injury in middle-aged women. Saudi Journal of Sports Medicine. 2018;18:67. [PMID: 10.4103/sjsm.sjsm_1_17].

11. Ballal MS, Khan Y, Hastie G, Hatcher A, Coogan S, McNicholas MJ. Functional outcome of primary hamstring anterior cruciate ligament reconstruction in patients with different body mass index classes. Arthroscopy: the journal of arthroscopic related surgery : official publication of the Arthroscopy Association of North America the International Arthroscopy Association. 2013;29:1314. 10.1016/j.arthro.2013.05.005]. [PMID: 23830220.

12. Bojicic KM, Beaulieu ML, Imaizumi Krieger DY, Ashton-Miller JA, Wojtys EM. Association Between Lateral Posterior Tibial Slope, Body Mass Index, and ACL Injury Risk. Orthop J Sports Med. 2017;5:2325967116688664. [PMID: 28255568 10.1177/2325967116688664].

13. Derraik JG, de Bock M, Hofman PL, Cutfield WS. Increasing BMI is associated with a progressive reduction in physical quality of life among overweight middle-aged men. Scientific reports. 2014;4:3677. DOI:10.1038/srep03677]. [PMID: 24419299.

14. Shimokochi Y, Shultz SJ. Mechanisms of noncontact anterior cruciate ligament injury. J AthI Train. 2008;43:396. 10.4085/1062-6050-43.4.396]. [PMID: 18668173.

\section{Tables}


Table 1: Baseline Characteristics of patients 


\begin{tabular}{|c|c|}
\hline Study variables & $\begin{array}{l}\mathrm{N}(\%) \\
(\mathrm{n}=289)\end{array}$ \\
\hline \multicolumn{2}{|l|}{ Age group in years } \\
\hline - $\quad 11-20$ years & $38(13.1 \%)$ \\
\hline - 21 - 30 years & $155(53.6 \%)$ \\
\hline - $\quad>30$ years & $96(33.2 \%)$ \\
\hline \multicolumn{2}{|l|}{ Gender } \\
\hline - Male & $284(98.3 \%)$ \\
\hline - Female & $05(01.7 \%)$ \\
\hline \multicolumn{2}{|l|}{ Nationality } \\
\hline - $\quad$ Saudi & $286(99.0 \%)$ \\
\hline - $\quad$ Non-Saudi & $03(01.0 \%)$ \\
\hline \multicolumn{2}{|l|}{ Type of sports } \\
\hline - $\quad$ Football & $182(63.0 \%)$ \\
\hline - $\quad$ Basketball & $04(01.4 \%)$ \\
\hline - $\quad$ Other sports & $15(05.2 \%)$ \\
\hline - Non-sports & $88(30.4 \%)$ \\
\hline $\mathrm{BMI} \mathrm{kg} / \mathrm{m}^{2}($ mean $\pm \mathrm{SD})$ & $27.6 \pm 04.8$ \\
\hline \multicolumn{2}{|l|}{ BMI group } \\
\hline - Normal & $86(29.8 \%)$ \\
\hline - Overweight & $116(40.1 \%)$ \\
\hline - $\quad$ Class I obesity & $63(21.8 \%)$ \\
\hline - $\quad$ Class II obesity & $22(07.6 \%)$ \\
\hline - $\quad$ Class III obesity & $02(0.70 \%)$ \\
\hline \multicolumn{2}{|l|}{ Leg Injured } \\
\hline - Left & $129(44.6 \%)$ \\
\hline - $\quad$ Right & $158(54.7 \%)$ \\
\hline - $\quad$ Both & $02(0.70 \%)$ \\
\hline \multicolumn{2}{|l|}{ Isolated } \\
\hline - Isolated & $113(39.1 \%)$ \\
\hline - $\quad$ Combined & $176(60.9 \%)$ \\
\hline
\end{tabular}




\begin{tabular}{|c|c|}
\hline \multicolumn{2}{|l|}{ Type of Injury } \\
\hline - $\quad$ Sport & $201(69.6 \%)$ \\
\hline - Non-sport & $88(30.4 \%)$ \\
\hline \multicolumn{2}{|l|}{ Classification of Injury } \\
\hline - Contact & $97(33.6 \%)$ \\
\hline - Non-contact & $192(66.4 \%)$ \\
\hline \multicolumn{2}{|l|}{ Mechanism of injury } \\
\hline - $\quad$ Fall & $37(12.8 \%)$ \\
\hline - Twisting & $163(56.4 \%)$ \\
\hline - Trauma & $89(30.8 \%)$ \\
\hline \multicolumn{2}{|l|}{ Duration } \\
\hline - $\quad<1$ month & $19(07.0 \%)$ \\
\hline - 1 - 11 months & $82(30.0 \%)$ \\
\hline - 1 - 3 years & $135(49.5 \%)$ \\
\hline - $\quad>3$ years & $37(13.6 \%)$ \\
\hline \multicolumn{2}{|l|}{ Type of graft } \\
\hline - Semi-T & $269(93.7 \%)$ \\
\hline - $\quad$ ВTВ & $18(06.3 \%)$ \\
\hline \multicolumn{2}{|l|}{ Source of graft } \\
\hline - $\quad$ Autograft & $284(99.0 \%)$ \\
\hline - $\quad$ Allograft & $03(01.0 \%)$ \\
\hline \multicolumn{2}{|l|}{ Mode of injury } \\
\hline - $\quad$ Reinjured & $74(25.6 \%)$ \\
\hline - $\quad$ Non-reinjured & $215(74.4 \%)$ \\
\hline \multicolumn{2}{|l|}{ ACL type } \\
\hline - Isolated ACL & $113(39.1 \%)$ \\
\hline - $\quad$ ACL with medial & $93(32.2 \%)$ \\
\hline - ACL with lateral & $26(09.0 \%)$ \\
\hline - ACL with both & $32(11.1 \%)$ \\
\hline - ACL with other ligaments & $25(08.7 \%)$ \\
\hline
\end{tabular}

ACL - Anterior Cruciate Ligament. 
Table 2: Relationship between BMI group and the baseline characteristics of patients ${ }^{(n=289)}$ 


\begin{tabular}{|c|c|c|c|c|}
\hline Factor & $\begin{array}{l}\text { Normal } \\
\text { N (\%) } \\
(\mathrm{n}=86)\end{array}$ & $\begin{array}{l}\text { Overweight } \\
\qquad \begin{array}{c}\text { N (\%) } \\
(n=116)\end{array}\end{array}$ & $\begin{array}{l}\text { Obese } \\
\mathrm{N}(\%) \\
(\mathrm{n}=87)\end{array}$ & P-value ${ }^{\S}$ \\
\hline \multicolumn{5}{|l|}{ Age group in years } \\
\hline - $11-20$ years & $17(19.8 \%)$ & $10(08.6 \%)$ & $11(12.6 \%)$ & \multirow[t]{3}{*}{0.065} \\
\hline - $21-30$ years & $48(55.8 \%)$ & 59 (50.9\%) & $48(55.2 \%)$ & \\
\hline - $\quad>30$ years & $21(24.4 \%)$ & $47(40.5 \%)$ & $28(32.2 \%)$ & \\
\hline \multicolumn{5}{|l|}{ Gender } \\
\hline - Male & $86(100 \%)$ & $114(98.3 \%)$ & $84(96.6 \%)$ & \multirow[t]{2}{*}{0.220} \\
\hline - Female & 0 & $02(01.7 \%)$ & $03(03.4 \%)$ & \\
\hline \multicolumn{5}{|l|}{ Type of sports } \\
\hline - Football & $67(77.9 \%)$ & $68(58.6 \%)$ & $47(54.0 \%)$ & \multirow[t]{2}{*}{$0.002 * *$} \\
\hline - Non-football & $19(22.1 \%)$ & $48(41.4 \%)$ & $40(46.0 \%)$ & \\
\hline \multicolumn{5}{|l|}{ Leg Injured } \\
\hline - $\quad$ Left & $37(43.0 \%)$ & $53(45.7 \%)$ & $39(44.8 \%)$ & \multirow[t]{3}{*}{0.518} \\
\hline - Right & $49(57.0 \%)$ & $61(52.6 \%)$ & $48(55.2 \%)$ & \\
\hline - Both & 0 & $02(01.7 \%)$ & 0 & \\
\hline \multicolumn{5}{|l|}{ Isolated } \\
\hline - Isolated & $45(52.3 \%)$ & $46(39.7 \%)$ & $22(25.3 \%)$ & \multirow[t]{2}{*}{$0.001 * *$} \\
\hline - Combined & $41(47.7 \%)$ & $70(60.3 \%)$ & $65(74.7 \%)$ & \\
\hline \multicolumn{5}{|l|}{ Type of Injury } \\
\hline - $\quad$ Sport & $71(82.6 \%)$ & $75(64.7 \%)$ & $55(63.2 \%)$ & \multirow[t]{2}{*}{$0.007 * *$} \\
\hline - Non-sport & $15(17.4 \%)$ & $41(35.3 \%)$ & $32(36.8 \%)$ & \\
\hline \multicolumn{5}{|l|}{ Classification of Injury } \\
\hline - Contact & $32(37.2 \%)$ & $39(33.6 \%)$ & $26(29.9 \%)$ & \multirow[t]{2}{*}{0.594} \\
\hline - Non-contact & $54(62.8 \%)$ & $77(66.4 \%)$ & $61(70.1 \%)$ & \\
\hline \multicolumn{5}{|l|}{ Mechanism of injury } \\
\hline - $\quad$ Fall & $06(07.0 \%)$ & $17(14.7 \%)$ & $14(16.1 \%)$ & \multirow[t]{3}{*}{0.212} \\
\hline - Twisting & $53(61.6 \%)$ & $59(50.9 \%)$ & $51(58.6 \%)$ & \\
\hline - Trauma & $27(31.4 \%)$ & $40(34.5 \%)$ & $22(25.3 \%)$ & \\
\hline \multicolumn{5}{|l|}{ Type of graft } \\
\hline - Semi-T & $80(93.0 \%)$ & $104(91.2 \%)$ & 85 (97.7\%) & \multirow[t]{2}{*}{0.164} \\
\hline - $\quad$ ВТВ & $06(07.0 \%)$ & $10(08.8 \%)$ & $02(02.3 \%)$ & \\
\hline
\end{tabular}




\begin{tabular}{|c|c|c|c|c|} 
Source of graft & & & \\
\hline • Autograft & $86(100 \%)$ & $113(99.1 \%)$ & $85(97.7 \%)$ & \multirow{2}{*}{0.323} \\
\hline Allograft & 0 & $01(0.90 \%)$ & $02(02.3 \%)$ & \\
\hline Mode of injury & & & & \\
\hline Reinjured & $14(16.3 \%)$ & $38(32.8 \%)$ & $22(25.3 \%)$ & \multirow{2}{*}{$0.029 * *$} \\
\hline - Non-reinjured & $72(83.7 \%)$ & $78(67.2 \%)$ & $65(74.7 \%)$ & \\
\hline
\end{tabular}

$\S$ P-value has been calculated using chi square test.

** Significant at $\mathrm{p} \leq 0.05$ level.

Table 3: Binary regression analysis to predict the effect of obesity from the selected baseline characteristics of patients ${ }^{(n=289)}$

\begin{tabular}{|c|c|c|c|}
\hline Factor & Odds Ratio & $95 \% \mathrm{CI}$ & P-value ${ }^{\S}$ \\
\hline \multicolumn{4}{|l|}{ Type of sports } \\
\hline - Football & 0.598 & $0.356-1.006$ & \multirow[t]{2}{*}{0.053} \\
\hline - Non-football & Ref & & \\
\hline \multicolumn{4}{|l|}{ Isolated } \\
\hline - Isolated & Ref & & \multirow[t]{2}{*}{$0.003 * *$} \\
\hline - Combined & 2.367 & $1.352-4.145$ & \\
\hline \multicolumn{4}{|l|}{ Type of Injury } \\
\hline - $\quad$ Sport & 0.982 & $0.408-2.367$ & \multirow[t]{2}{*}{0.126} \\
\hline - Non-sport & Ref & & \\
\hline \multicolumn{4}{|l|}{ Mode of injury } \\
\hline - $\quad$ Reinjured & 0.720 & $0.614-2.025$ & \multirow[t]{2}{*}{0.385} \\
\hline - $\quad$ Non-reinjured & Ref & & \\
\hline
\end{tabular}

CI - Confidence Interval.

** Significant at $\mathrm{p} \leq 0.05$ level 